\title{
Comparative Analysis of the Effect of the Different Adaptations of the Squat Exercise on the Knee Frontal Plane Projection Angle
}

\section{Análise Comparativa do Efeito de Diferentes Adaptações de Agachamento no Ângulo de Projeção do Plano Frontal do Joelho}

\author{
Yasmim Hikari Nakagima; Lorrane Nascimento dos Santos ${ }^{\mathrm{a}}$; Thiago Domingues Stocco*b \\ aSanto Amaro University, Physical Therapy Course. SP, Brazil. \\ ${ }^{b}$ State University of Campinas, Stricto Sensu Program in Medical Clinic. SP, Brazil. \\ *E-mail: tdstocco@live.com e tstocco@prof.unisa.br \\ Recebido em: 27/01/2020 \\ Aprovado em: 28/04/2020
}

\begin{abstract}
Closed kinetic chain exercises have been employed in rehabilitation and muscle strengthening programs, such as squatting. During the movement of the squat dynamic valgus, a change that affects all kinematics of the lower limb, tends to become exacerbated, necessitating adaptations in order to minimize the biomechanical disorder. Although studies have shown the effectiveness of squatting exercises, there is a lack of evidence to demonstrate, comparatively, the effectiveness of different adaptations in the decrease of dynamic valgus. The objective of the study was to evaluate to identify the efficacy of different adaptations in squatting exercise in the reduction of dynamic valgus. Therefore, study volunteers $(\mathrm{n}=30)$ performed three types of squats: free squatting, squatting with elastic band and squatting with verbal command. The dynamic valgus wasmeasured by the knee frontal plane projection angle during the squatting movements, through captured images and analyzed by the software Tracker and ImageJ. Despite more cases in women, in both sexes, free squatting presented greater cases of medicalization of the knee than in comparison to the other two adaptations. Although both squat adaptations presented positive results, only squatting with verbal command showed a significant reduction of the dynamic valgus pointing out that this is the best adaptation treated.
\end{abstract}

Keywords: Genu Valgum. Exercise Therapy. Motor Activity.

\section{Resumo}

Exercícios de cadeia cinética fechada vêm sendo empregados em programas de reabilitação e fortalecimento muscular, como é o caso do agachamento. Durante o movimento de agachamento o valgo dinâmico, alteração que afeta toda cinemática do membro inferior, tende a se tornar exacerbado, sendo necessárias adaptações com $\theta$ intuito de minimizar o distúrbio biomecânico. Embora estudos tenham mostrado a eficácia dos exercícios de agachamento, faltam evidências que demonstrem, comparativamente, a efetividade de diferentes adaptações na minimização do valgo dinâmico. O objetivo do estudo foi identificar a eficácia de diferentes adaptações na execução do exercício de agachamento na redução do valgo dinâmico. Para tanto, os voluntários do estudo $(n=30)$ três tipos de agachamentos: agachamento livre, agachamento com banda elástica e agachamento com comando verbal. O valgo dinâmico foi mensurado mediante o ângulo de projeção no plano frontal do joelho durante os movimentos de agachamento, através de imagens capturadas e posteriormente analisadas pelos softwares Tracker e ImageJ. Apesar de mais casos em mulheres, em ambos os sexos, o agachamento livre apresentou maiores casos de medicalização do joelho do que nas outras duas adaptações. Embora ambas adaptações de agachamento apresentaram resultados positivos, apenas o agachamento com comando verbal apresentou redução significativa do valgo dinâmico, apontando ser esta a melhor adaptação tratada.

Palavras-chaves: Geno Valgo. Terapia por Exercício. Atividade Motora.

\section{Introduction}

Closed-chain kinetics exercises (CCF) are defined as those in which distal segments are supported on a surface, which limit movement and define a direction ${ }^{1,2}$. This modality of physical exercise requests the movement of more than one articulation for its effect ${ }^{1}$.

In addition to stimulating the proprioceptive system, $\mathrm{CCF}$ exercises require coactivation and co-contraction of both agonist and antagonist muscles, providing better joint stability $^{2,3}$ For this reason, they are clinically safer and often indicated for knee joint rehabilitation programs because they reduce shear forces and cause lower stresses in joint structures under recovery ${ }^{1,3,4}$.

Although CCF exercises are effective in the development of lower limb muscles, they should be used in the correct manner in individuals with patellofemoral and ligamentar alterations, especially in the larger knee flexion angles where the translation and compression forces increase ${ }^{5}$.

Among the CCF exercises, squatting receives special attention $^{6-10}$. This is a multiarticular exercise, in which there is a triple simultaneous flexion of lower limb joints: Hip, knee and ankle $\mathrm{e}^{1,11}$. The activation of agonist and antagonist muscles of the lower limbs favor dynamic stability during movements and help in postural control and prevention of misalignments, as is the case with dynamic valgus. The dynamic valgus of the lower limbs occurs when the foot is fixed in the ground and the center of the knee joint moves medially in relation to the hip and foot during a dynamic movement, thus preventing adequate alignment ${ }^{12,13}$. 
The misalignment of the dynamic valgus creates a vector of lateral force, increasing the pressure on the lateral facet of the patella with the lateral femoral condyle, becoming an important risk factor for the development of Patellofemoral Pain Syndrome (PFPS). This misalignment also increases ligament tensions predisposing to injuries in ligaments and other periarticular structures ${ }^{12,14,15}$.

Studies have shown that the neuromuscular control deficit of hip and pelvis stabilizers (abductor, external rotator and hip extensors) are the main responsible for the control of dynamic valgus $^{16-18}$. The posterolateral hip complex, formed by the abductor and extensor muscles, has a significant correlation with dynamic valgus control ${ }^{12,19}$. Also, the middle gluteus receives special attention because it plays an important role in the femur external rotation and abduction 14,20. The muscular weakness of the medium gluteus generates the fall of the contralateral pelvis, medial peak rotation and adduction of the ipsilateral femur, increasing the compressive forces in the knee joint, this contributes to the exacerbation of dynamic valgus and the development of lesions ${ }^{12,14}$.

Currently, in the rehabilitation protocols, the prescription of CCF exercises, such as squatting, has been emphasized, in which the dynamic valgus is usually exacerbated. Thus, adaptations during squatting have been made to improve activation of specific muscles and reduce the dynamic valgus during movement ${ }^{1,21}$. Among some adaptations free squatting, squatting with different feet positions and squatting with elastic band at knee level stand out ${ }^{22-24}$. Furthermore, verbal command is capable of correcting inefficient movements and patterns in a simple and effective manner ${ }^{25}$. Studies have shown that patients can respond more accurately to simple verbal commands, such as reducing knee adduction during squat ${ }^{26,27}$.

Although studies have shown the effectiveness of squatting exercises, there is a lack of evidence to demonstrate, comparatively, the effectiveness of different adaptations in the decrease of dynamic valgus. ${ }^{28-30}$. Thus, the objective of the study was to identify the efficacy of different adaptations of the squatting exercise in minimizing the immediate dynamic valgus by analyzing the projection angle in the frontal plane (PAPF) of the knee.

\section{Material and Methods}

\subsection{Sample}

The sample consisted of 30 healthy volunteers ( 15 women and 15 men) with a mean age equivalent to 21 years $( \pm 3.35$ years), who did not practice physical exercise regularly for more than 6 months. Exclusion criteria were the performance of any type of surgery in the lower limbs, with pathologies that cause any alteration in the lower limbs or make it impossible to perform the tests.

The volunteers were duly informed about the research procedures and agreed to participate by signing The Free and informed Consent Term, following the norms present in
Resolution $n^{\circ} 466$ of the National Health Council. The study was subjected and approved by the Ethics and Research Committee of Santo Amaro University, São Paulo, Brazil (opinion number 2.887.359).

\subsection{Experimental design}

The application of the adaptations of the squat exercises was carried out in a single group, in order to identify the option that is the most effective in reducing the dynamic valgus compared to the voluntary change itself in the three adaptations.

The individuals were verbally oriented to perform the exercises, and the movement speed and flexion degree were demonstrated; however, no information regarding knee and hip direction was available. The participants were able to test the execution of each squat exercise for a maximum of three times with one minute of interval prior to final execution.

The volunteers were placed on foot, barefoot to avoid variability in different materials, and the squat movement was performed slowly up to the 90th angle and returned to the initial position. The individuals repeated the same movement for each type of squat adaptation in alternate days, as described in Chart 1, and three video images of each type of squat were recorded, being considered the mean value for analysis purposes.

Table 1-Sequence of the adjustments to the squat exercises

\begin{tabular}{|c|l|}
\hline Day & \multicolumn{1}{c|}{ Adaptation } \\
\hline 1 & Free Squat \\
\hline 2 & Squat with Elastic \\
\hline 3 & Squat With Verbal Command \\
\hline
\end{tabular}

Source: Research data.

\section{(a) Free Squat}

Performed only with body weight, in which the individual positioned in upright position, knees and hips in extension and displacement of the lower limbs in the same line of the shoulder. The triple eccentric flexion of hips, knees and ankles was performed, reaching the 90 degree angle, in the sequence, returning to the initial position ${ }^{22,31}$.

\section{(b) Squat with Elastic Band}

Performed with elastic band, while the individual performs the free squat movement. The addition of elastic band in the most distal part of the thigh in free squatting provides greater external resistance and tactile stimulation, providing greater neuromuscular capacity ${ }^{23,24}$.

\section{(c)Squat With Verbal Command}

Performed in the same way as free squat, but with simple verbal commands before movement. Sensory stimuli present alterations in exercise execution, considering that verbal command helps proprioception of knee and hip alignment avoiding excessive dynamic valgus ${ }^{27}$. 


\subsection{Data analysis}

The kinematic analysis of the dynamic knee valgus was performed by means of the APPF dimension. Idealized as a two-dimensional analysis resource, APPF is a simple, versatile and low-cost method capable of measuring the alignment of the lower limbs in the frontal plane, considering that the closer to the physiological angle $\left(175-180^{\circ}\right)$, the better ${ }^{32,33}$. The analysis of lower limb alignment during squat is performed from a digital image of the lower edge taken during the knee bending phase at squat.

To capture the images, the camera was leveled at knee height and fixed on a tripod two meters away. Adhesive markers were placed in three points: In the center of the patella; antero-superior iliac spine; and in the center of the ankle, between the lateral and medial malleolus ${ }^{12,13,34}$.

APPF was recorded at the highest dynamic valgus peak of the knee. The images were analyzed by the Tracker (https:// physlets.org/tracker/) and ImageJ software (https://imagej. nih.gov/ij/) in order to measure the variation of APPF during the squat movements (Figure 1).

Figure 1 - APPF Analysis performed by ImageJ Software

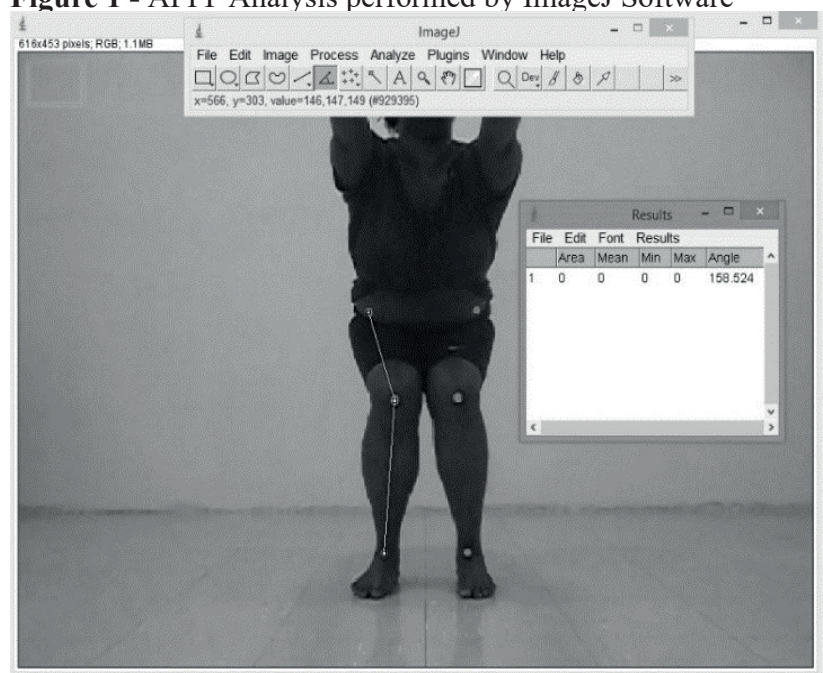

Source: Research data.

\subsection{Statistical analysis}

Descriptive analysis was performed using the sampling data of each squat exercise. For this purpose, the results were expressed by means of mean values \pm standard deviation and compared by means of the procedures of the analysis of variance (ANOVA), with a subsequent Tukey test. The statistical software Minitab ${ }^{\circledR}$ (version 17, Minitab Inc., State College, USA) was used.

\section{Results and Discussion}

All volunteers completed the study without intercurrences. Of the 30 participants, $60 \%(\mathrm{n}=18)$ presented dynamic valgus in at least one of the three squatting adaptations. In the comparison between both genders, $63.6 \%$ of women presented excessive dynamic valgus, while in men this condition was observed in $50 \%$ of the volunteers.

Of the 90 squatting analyzed movements the dynamic valgus was more present in the free mode, with a record of 18 cases, followed by the squatting adaptation with elastic band with nine cases of dynamic valgus. In the squatting associated with verbal command, only seven individuals presented knee medial collapse during the $23.3 \%(n=7)$ movement of the volunteers presented dynamic valgus in the 3 squatting adaptations.

The APPF recorded at free squatting showed an average value of $168.4 \pm 5.8$ degrees, while in the cases of squatting with elastic band and squatting associated to verbal command, the mean values were equivalent to $174.3 \pm 2.7$ and $178.5 \pm 3.7$, respectively (Figure 3). The results showed a significant difference favorable to squatting with verbal command compared to the other two adaptations made in the study. However, no statistically significant differences were identified between free squat and squat movements with elastic band.

Figure 2 - Frontal plane projection Angle (APPF) of the knee recorded in the three squat movements. Free vs. Elastic band $(\mathrm{p}=0.114)$, Free vs. Verbal command $(\mathrm{p}=0.001)$, elastic Band vs. Verbal command $(\mathrm{p}=0.019)$.

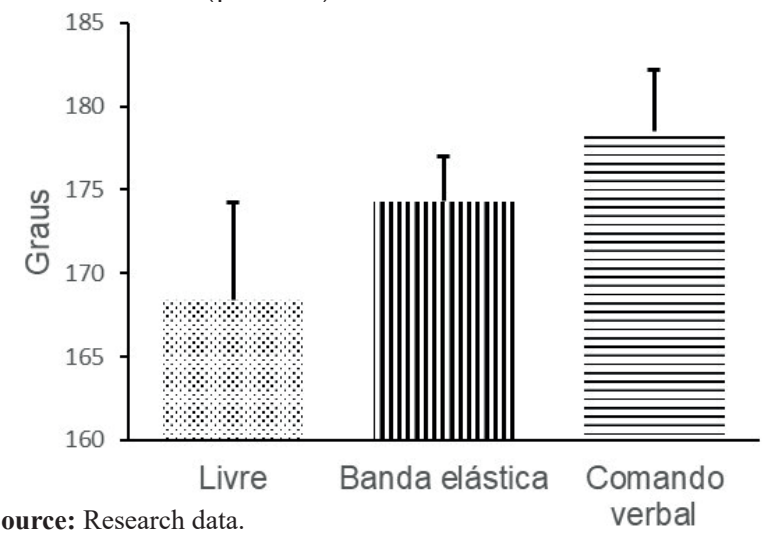

Also, as shown in Figure 3, most individuals presented better performance in the squat movement associated with verbal command, followed by elastic band, and finally, free squat.

Figure 3 - Number of volunteers who achieved better results in each squat variation.

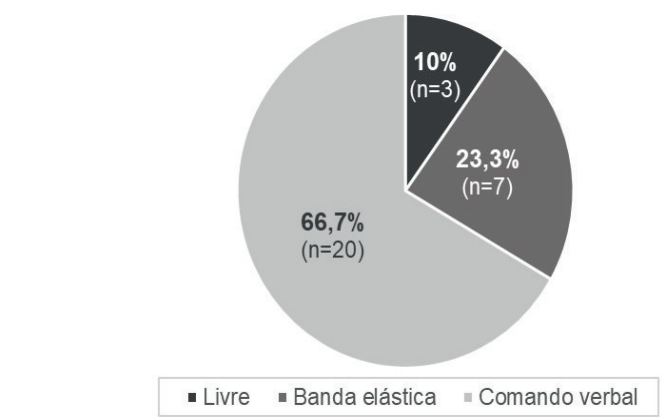

Source: Research data.

The objective of the study was to evaluate to identify 
the efficacy of different adaptations in squatting exercise in the reduction of the knee dynamic valgus. For this purpose, the knee joint angular displacement was recorded using the APPF of the dominant lower limb, and the results found showed significant differences $(p<0.05)$, among the squatting adaptations.

As in this study, other authors have identified that women tend to present a greater dynamic valgus than $\operatorname{men}^{20,35,36}$. Some authors justify this finding due the fact that women show lower articular stiffness, delayed muscle activation and less favorable anatomical structure ${ }^{35,42}$.

Of the most cited causes that may lead to an increase in dynamic valgus, muscular weakness and neuromuscular control deficit may be highlighted ${ }^{12,14,16-19}$. Since one of the inclusion criteria of this study was the lack of physical exercises in the last six months, it is assumed that the participants were sedentary and potentially predisposed to present muscle weakness and limitations, this explains the high rate $(60 \%)$ of volunteers with excessive dynamic valgus.

It can be suggested that the high dynamic valgus index of the knee is directly associated with the muscular weakness of hip and pelvis stabilizers, especially of the medium gluteus that plays an important role in stabilizing this region. This association corroborates with the study by Reiman et $a .^{43}$, who compared the various levels of activation of the medium gluteus using electromyography technique in the performance of different exercises, and identified that in more dynamic activities there was a greater activation of this muscle, operated as a hip abductor to keep the pelvis position level and as a lateral hip rotator to minimize the knee valgus collapse. On the other hand, Russel et al. ${ }^{20}$ hypothesized that the activation time of the medium gluteus becomes more important than the activation level for the control of the dynamic valgus.

Another hypothesis for the high number of cases of dynamic valgus is the imbalance in the activation of lower limb muscles by neuromuscular control. A study carried out by Palmierismith et al. $^{40}$ confirmed that the pre-activation of the medium gluteus does not significantly influence the dynamic valgus peak of the knee, but the imbalance of the activation of the thigh lateral and medial muscles has a direct influence on the control of the valgus and varus of the knee.

The low level of success in the control of dynamic valgus in the squatting movement with elastic band in comparison to the squatting with verbal command observed in the study may also be associated to the muscle weakness of lower limbs, mainly of lateral rotator and hip abductor muscles, they probably did not overcome the force exerted by the elastic band, even though it was used primarily for tactile stimulation purposes and with low resistance. Israeli et al. ${ }^{44}$ conducted a study with the objective of investigating kinetic and kinematic variables among squats performed with and without elastic bands. It was concluded that the elastic band significantly increases the power and speed values during the first part of the eccentric phase and the last part of the concentric phase of the squat, and that the activity of the vastus lateralis muscle during the condition of the elastic band was significantly higher during the first portion of the eccentric phase and the last portion of the concentric phase. Based on these findings and correlating with the sedentary sample of the present study, the result obtained for this squatting adaptation is justified.

The reduction of dynamic valgus through treatment programs and adaptation of exercises has been discussed in the scientific environment. Although there are several types of squat, such as changes in the rotation of the foot during exercise, studies have shown divergent results in relation to the decrease in dynamic valgus through external rotation (toeout) and internal rotation (toe-in) during CCF exercises ${ }^{45,46}$. In our study, these variations were not analyzed, since, with the rotation of the foot, the knee moves beyond the frontal plane, making it impossible to reliably analyze the dynamic valgus by APPF and, therefore, the use of three-dimensional technique is necessary.

Verbal command squatting showed an improvement in the control of the dynamic valgus with simple verbal guidelines, such as instructing the volunteer to keep the knee joint aligned with the foot in the entire arch of the movement. This finding corroborates the results of a study carried out by Cowling et al. ${ }^{26}$ with the objective of analyzing the efficacy of verbal instructions in the landing activity, concluding that the individuals present a good response to the simple verbal instructions. Baldon et al. ${ }^{47}$ also found that verbal feedback on the proper alignment of lower limbs during functional activities has good results in women with patellofemoral pain syndrome.

\section{Conclusion}

The results indicated significant differences among the squatting adaptations. Squatting associated with verbal command has promoted more accentuated improvements in the minimization of the immediate dynamic valgus, thus suggesting that this would be the best adaptation among the three studied ones.

\section{References}

1. Sousa CDO, Ferreira JJDA, Veras Medeiros ACL, De Carvalho AH, Pereira RC, Guedes DT, et al. Atividade eletromiográfica no agachamento nas posições de $40^{\circ}, 60^{\circ} \mathrm{e}$ $90^{\circ}$ de flexão do joelho. Rev Bras Med Esporte 2007;13:3106. doi:10.1590/S1517-86922007000500006.

2. Araujo AJS, Silva Junior WM. The Q angle analysis, during resistance training, on open kinematics chain and intermidiate closed kinematics chain, through photogrametry. Rev Bras Ciênc Esp 2014;36:327-39. doi:10.1590/S010132892014000200004 .

3. Bunton EE, Pitney WA, Cappaert TA, Kane AW. The role of limb torque, muscle action and proprioception during closed kinetic chain rehabilitation of the lower extremity. J Athl Train 1993;28:10-20.

4. Blackburn JR, Morrissey MC. The Relationship between open and closed kinetic chain strength of the lower limb and 
jumping performance. J Orthop Sport Phys Ther 2013;27:4305. doi:10.2519/jospt.1998.27.6.430.

5. Bynum EB, Barrack RL, Alexander AH. Open Versus Closed Chain Kinetic Exercises After Anterior Cruciate Ligament Reconstruction:AProspective Randomized Study. Am J Sports Med 1995;23:401-6. doi:10.1177/036354659502300405.

6. Kianifar R, Lee A, Raina S, Kulic D. Automated assessment of dynamic knee valgus and risk of knee injury during the single leg squat. IEEE J Transl Eng Heal Med 2017;5:1-13. doi:10.1109/JTEHM.2017.2736559.

7. Dill KE, Begalle RL, Frank BS, Zinder SM, Padua DA. Altered knee and ankle kinematics during squatting in those with limited weight-bearing-lunge ankle-dorsiflexion range of motion. J Athl Train 2014;49:723-32. doi:10.4085/10626050-49.3.29.

8. Donohue MR, Ellis SM, Heinbaugh EM, Stephenson ML, Zhu Q, Dai B. Differences and correlations in knee and hip mechanics during single-leg landing, single-leg squat, double-leg landing, and double-leg squat tasks. Res Sport Med 2015;23:394-411. doi:10.1080/15438627.2015.107641 3.

9. Longpré HS, Acker SM, Maly MR. Muscle activation and knee biomechanics during squatting and lunging after lower extremity fatigue in healthy young women. J Electromyogr Kinesiol 2015;25:40-6. doi:10.1016/j.jelekin.2014.08.013.

10. Cotter JA, Chaudhari AM, Jamison ST, Devor ST. Knee Joint Kinetics in Relation to Commonly Prescribed Squat Loads and Depths. J Strength Cond Res 2013;27:1765-74. doi:10.1519/JSC.0b013e3182773319.

11. Moser ADL, Malucelli MF, Bueno SN. Cadeia cinética aberta e fechada: uma reflexão crítica. Fisioter Mov 2010;23:64150. doi:10.1017/CBO9781107415324.004.

12. Almeida GPL, Carvalho e Silva APMC, França FJR, Magalhães MO, Burke TN, Marques AP. Does anterior knee pain severity and function relate to the frontal plane projection angle and trunk and hip strength in women with patellofemoral pain? J Bodyw Mov Ther 2015;19:558-64. doi:10.1016/j.jbmt.2015.01.004.

13. Holden S, Boreham C, Doherty C, Delahunt E. Twodimensional knee valgus displacement as a predictor of patellofemoral pain in adolescent females. Scand J Med Sci Sport 2017;27:188-94. doi:10.1111/sms.12633.

14. Maia MS, Carandina MHF, Santos MB, Cohen M. Associação do valgo dinâmico do joelho no teste de descida de degrau com a amplitude de rotação medial do quadril. Rev Bras Med Esp 2012;18:164-6. doi:10.1590/S1517-86922012000300005.

15. Prins MR, van der Wurff P. Females with patellofemoral pain syndrome have weak hip muscles: a systematic review. Aust J Phys 2009;55:9-15. doi:10.1016/S0004-9514(09)70055-8.

16. Almeida GPL, De Moura Campos Carvalho e Silva AP, França FJR, Magalhães MO, Burke TN, Marques AP. Relationship between frontal plane projection angle of the knee and hip and trunk strength in women with and without patellofemoral pain. J Back Musculoskelet Rehabil 2016;29:259-66. doi:10.3233/BMR-150622.

17. Powers CM. The influence of abnormal hip mechanics on knee injury: a biomechanical perspective. J Orthop Sport Phys Ther 2010;40:42-51. doi:10.2519/jospt.2010.3337.

18. Zazulak BT, Hewett TE, Reeves NP, Goldberg B, Cholewicki J. Deficits in neuromuscular control of the trunk predict knee injury risk: A prospective biomechanical- epidemiologic study. Am J Sports Med 2007;35:1123-30. doi:10.1177/0363546507301585.

19. Long-Rossi F, Salsich GB. Pain and hip lateral rotator muscle strength contribute to functional status in females with patellofemoral pain. Physiother Res Int 2010;15:57-64. doi:10.1002/pri.449.

20. Russel K, Palmieri R, Zinder S, Ingersoll C. Sex differences in valgus knee angle during a single leg drop jump. J Athl Train 2006;41:166-71.

21. Souza MC, Jennings F, Morimoto H, Natour J. Swiss ball exercises improve muscle strength and walking performance in ankylosing spondylitis: a randomized controlled trial. Rev Bras Reumatol 2017;57:45-55. doi:10.1016/j. rbre.2016.09.009.

22. Reiser FC, Souza WC de, Mascarenhas LPG, Grzelczak MT. Atividade muscular de membros inferiores no exercício de agachamento. Rev Acta Bras Mov Hum 2014;4:90-102. doi:10.5935/abc.20160042.

23. Saeterbakken AH, Andersen V, Van Den Tillaar R. Comparison of Kinematics and Muscle Activation in Free-Weight Back Squat with and Without Elastic Bands. J Strength Cond Res 2016;30:945-52. doi:10.1519/JSC.0000000000001178.

24. Atle H. Saeterbakken, Vidas Andersen, Maria K. Kolnes MSF. Effects of replacing free weights with elastic band resistance in squats on trunk muscle activation. J Strength Cond Res 2014;28:3056-62.

25. Galdino L, Varise EM. Os efeitos do comando verbal na reabilitação física Effects of verbal command in physical rehabilitation. Rev Neurocienc 2010;18:95-102.

26. Cowling EJ. Effect of verbal instructions on muscle activity and risk of injury to the anterior cruciate ligament during landing* Commentary. Br J Sports Med 2003;37:126-30. doi:10.1136/bjsm.37.2.126.

27. Silva SB, Abreu LC, Valenti VE, Nogueira DV, Moraes ÉR, Natividade $\mathrm{V}$, et al. Verbal and visual stimulation effects on rectus femoris and biceps femoris muscles during isometric and concentric. Int Arch Med 2013;6:1-7. doi:10.1186/17557682-6-38.

28. Andersen V, Fimland MS, Brennset, Haslestad LR, Lundteigen MS, Skalleberg K, et al. Muscle activation and strength in squat and bulgarian squat on stable and unstable surface. Int J Sports Med 2014;35:1196-202. doi:10.1055/s-0034-1382016.

29. Beattie K, Kenny IC, Lyons M, Carson BP. The effect of strength training on performance in endurance athletes. Sport Med 2014;44:845-65. doi:10.1007/s40279-014-0157-y.

30. Biernat R, Trzaskoma Z, Trzaskoma Ł, Czaprowski D. Rehabilitation protocol for patellar tendinopathy applied among 16- to 19-year old volleyball players. J Strength Cond Res 2014;28:43-52. doi:10.1519/JSC.0b013e31829797b4.

31. Schoenfeld BJ. Squatting kinematics and kinetics and their application to exercise performance. J Strength Cond Res 2010;24:3497-506. doi:10.1519/JSC.0b013e3181bac2d7.

32. Colclough A, Munro AG, Herrington LC, McMahon JJ, Comfort $\mathrm{P}$. The effects of a four week jump-training program on frontal plane projection angle in female gymnasts. Phys Ther Sport 2018;30:29-33. doi:10.1016/j.ptsp.2017.11.003.

33. Comfort P, Colclough A, Herrington L. A Comparison of Frontal Plane Projection Angle Across Landing Tasks in Female Gymnasts. Int J Athl Ther Train 2016;21:42-7. doi:10.1123/ijatt.2015-0068. 
34. Willson JD, Davis IS. Utility of the Frontal Plane Projection Angle in Females With Patellofemoral Pain. J Orthop Sport Phys Ther 2008;38:606-15. doi:10.2519/jospt.2008.2706.

35. Wei-Hsiu Hsu, Jesse A. Fisk, Yuji Yamamoto, Richard E. Debski SL-YW. Differences in torsional joint stiffness a human cadaveric study. Am J Sports Med 2006;34:765-70. doi:10.1177/0363546505282623.

36. Palmieri-Smith RM, McLean SG, Ashton-Miller JA, Wojtys EM. Association of quadriceps and hamstrings cocontraction patterns with knee joint loading. J Athl Train 2009;44:256-63. doi:10.4085/1062-6050-44.3.256.

37. Carcia CR, Shultz SJ, Granata KP, Gansneder BM, Perrin $\mathrm{DH}$. Knee ligament behavior following a controlled loading protocol does not differ by menstrual cycle day. Clin Biomech (Bristol, Avon) 2004;19:1048-54. doi:10.1016/j. clinbiomech.2004.07.006.

38. Jacobs CA, Uhl TL, Mattacola CG, Shapiro R, Rayens WS. Hip abductor function and lower extremity landing kinematics: sex differences. J Athl Train 2007;42:76-83.

39. Myer GD, Ford KR, Hewett TE. The effects of gender on quadriceps muscle activation strategies during a maneuver that mimics a high ACL injury risk position. J Electromyogr Kinesiol 2005;15:181-9. doi:10.1016/j.jelekin.2004.08.006.

40. Palmieri-smith RM, Wojtys EM, Ashton-miller JA. Association between preparatory muscle activation and peak valgus knee angle. J Electromyogr Kinesiol 2008;18:973-9. doi:10.1016/j.jelekin.2007.03.007.
41. Schmitz RJ, Shultz SJ, Nguyen AD. Dynamic valgus alignment and functional strength in males and females during maturation. J Athl Train 2009;44:26-32. doi:10.4085/10626050-44.1.26.

42. Quatman CE, Ford KR, Myer GD, Hewett TE. Maturation leads to gender differences in landing force and vertical jump a longitudinal study. Am J Sports Med 2006;34:806-13. doi:10.1177/0363546505281916.

43. Reiman MP, Bolgla LA, Loudon JK. A literature review of studies evaluating gluteus maximus and gluteus medius activation during rehabilitation exercises. Phys Theor Pract 2012;28:257-68. doi:10.3109/09593985.2011.604981.

44. Israetel MA, McBride JM, Nuzzo JL, Skinner JW, Dayne AM. Kinetic and kinematic differences between squats performed with and without elastic bands. J Strength Cond Res 2010;24:190-4. doi:10.1519/JSC.0b013e31819b7995.

45. Ishida T, Yamanaka M, Takeda N, Aoki Y. Knee rotation associated with dynamic knee valgus and toe direction. Knee 2014;21:563-6. doi:10.1016/j.knee.2012.12.002.

46. Teng PSP, Kong PW, Leong KF. Effects of foot rotation positions on knee valgus during single-leg drop landing: Implications for ACL injury risk reduction. Knee 2017;24:547-54. doi:10.1016/j.knee.2017.01.014.

47. Baldon RM, Serrão FV, Scattone Silva R, Piva SR. Effects of functional stabilization training on pain, function, and lower extremity biomechanics in women with patellofemoral pain: a randomized clinical trial. J Orthop Sport Phys Ther 2014;44:240-A8. doi:10.2519/jospt.2014.4940 